\title{
PROFESSORES SOB O OLHAR VIGILANTE DO ESTADO: O SISTEMA DE RECOMPENSAS E PUNIÇÕES COMO ESTRATÉGIA DE MODELIZAÇÃO DA PRÁTICA DOCENTE EM MINAS GERAIS
}

\author{
Valéria Moreira Rezende \\ Universidade Federal de Uberlândia - UFU \\ Rogéria Moreira Rezende Isobe \\ Universidade Federal do Triângulo Mineiro - UFTM
}

\section{RESUMO}

Este artigo busca contribuir para compreensão da constituição histórica da educação brasileira examinando aspectos da política educacional e das práticas escolares em Minas Gerais decorrentes da Reforma João Pinheiro em 1906. No âmbito de uma política educacional caracterizada pela ação reguladora e centralizadora do governo, as imagens do professor e da escola são construídas a partir da ótica dos inspetores técnicos. A análise do corpus empírico que compõe o acervo do Arquivo Público Mineiro - relatórios de inspeção, relatórios do secretário do Interior, correspondências - evidencia que os inspetores técnicos são destacados para transformar o olhar vigilante do Estado em palavra expressa nos relatórios que iriam, por sua vez, balizar as estratégias de modelização da prática docente por meio de um sistema de recompensas ou punições. Observaram-se práticas de resistência de alguns professores que questionavam as informações contidas nos relatórios, evidenciando tensões e conflitos nos processos de apropriação dos modelos pedagógicos em Minas Gerais.

Palavras-chave: Políticas Educacionais; Prática docente; Inspeção Escolar; Reforma João Pinheiro.

\section{TEACHERS UNDER STATE'S WATCHFUL EYE: THE REWARD AND PUNISHMENT SYSTEM AS STRATEGY TO IMPOSE TEACHING PRACTICE MODELS}

\begin{abstract}
This article seeks to contribute to a historical understanding of Brazilian education development. It focuses on educational policy aspects and on school practice derived from the 1906 educational reform João Pinheiro's government carried out in Minas Gerais state. As part of an educational policy characterized by regulation and centralization, school inspectors built an image of the teacher and of the school in their official communication with the government. The analysis of a set of inspection reports, Home Secretary reports, and correspondences shows that the function of inspecting was created so that inspectors could be the state's watchful eye who translated into written word what they saw in schools. Their reports would be considered in case of imposing models to teaching practices through a system of rewards and punishments. Some teachers expressed attitudes of resistance to the point of questioning their reports' reliability. In other words, tensions and conflicts marked the processes of imposing pedagogical models in Minas Gerais.

Keywords: Educational policies; Teaching practice; School inspection; João Pinheiro reform.
\end{abstract}




\section{Introdução}

Este trabalho aborda uma temática que tem sido objeto de interesse nos estudos e pesquisas desenvolvidas pelas autoras - tanto na perspectiva histórica como na abordagem contemporânea - nucleadas em torno de um campo de questões relativas aos impactos das políticas educacionais brasileiras sobre o trabalho docente e a organização do ensino. Em tais pesquisas busca-se, por um lado, analisar a pluralidade de dispositivos de normatização e estratégias governamentais de controle e imposição de determinadas práticas educativas nas escolas. Por outro lado, tenciona-se apreender as tensões, dissensões, resistências e conflitos que envolvem os sujeitos escolares nas práticas de apropriação de modelos pedagógicos em diferentes temporalidades históricas.

Para este artigo serão apresentados resultados de investigação com o objetivo de contribuir para a compreensão da constituição histórica da educação brasileira a partir da análise das experiências ocorridas âmbito da Reforma João Pinheiro em 1906. O foco analítico são as representações construídas sobre os professores pelos inspetores técnicos e as estratégias de modelização da prática docente mobilizadas pelo governo do estado. Busca-se colocar em cena as tensões entre os agentes estatais estrategicamente posicionados e especialmente destacados para modelar as práticas de ensino e os professores, cujas práticas eram alvo das tentativas de controle no âmbito de uma política educacional caracterizada pela ação reguladora e centralizadora do governo estadual.

O corpus empírico consiste em um conjunto de documentos que compõe o acervo do Arquivo Público Mineiro: relatórios de inspeção, relatórios do secretário do Interior e correspondências. O procedimento de crítica documental se nutre dos pressupostos da história cultural tendo como principal referência de análise o conceito de representação formulado por Chartier (1990, p. 16), uma vez que permite o exame dos documentos, entendendo-os como prática discursiva que dá a ver as representações perspectivadas pelas posições ocupadas por seus autores, pois estas práticas "são sempre determinadas pelos interesses do grupo que as forjam. Daí, para cada caso, o necessário relacionamento dos discursos proferidos com a posição de quem os utiliza". Ao discorrer sobre o conceito de representação o autor destaca a importância de compreender que as percepções do social não se configuram como discursos neutros, mas "produzem estratégias e práticas (sociais, escolares, políticas) que tendem a impor uma autoridade à custa de outras" de forma a "legitimar um projeto reformador ou a justificar, para os próprios indivíduos, as suas escolhas e condutas" (idem, p. 17).

Nessa perspectiva, foi possível estabelecer um critério de leitura e tratamento das fontes, atento ao lugar de produção do documento, buscando-se historicizar sua linguagem, problematizando-se seus limites e as circunstâncias de sua produção. Considerou-se que aqueles documentos veiculam uma determinada representação que tenta se impor a outras representações, pois são fortemente marcados pelas estratégias de implementação de determinadas práticas escolares preconizadas pelos reformadores da educação.

$\mathrm{O}$ artigo foi organizado em três seções. A primeira apresenta aspectos conjunturais da Reforma João Pinheiro no âmbito do projeto civilizador republicano. Ressalta-se a centralidade da escola na legitimação do novo regime e a relevância do serviço de inspeção na implementação da Reforma. A segunda seção analisa a avaliação docente nos relatos de inspeção buscando aprender os critérios que distinguiam o "bom" e o "mau" professor. A terceira seção examina o sistema de recompensas e punições operacionalizado pela Secretaria do Interior a partir das informações constantes dos relatórios de inspetoria 
técnica do ensino sobre os professores que atuavam nas escolas primarias de Minas Gerais. Por fim, serão apresentadas algumas considerações finais que sumarizam os principais resultados da pesquisa.

\section{A Reforma João Pinheiro em Minas Gerais: Projeto de modernização educacional e política de controle do ensino}

Em Minas Gerais, o projeto de modernização idealizado por intelectuais e políticos republicanos no início do século XX visava aliar o progresso material e econômico da sociedade ao "progresso das mentes", buscando "incorporar culturalmente os sujeitos sociais em suas diferentes manifestações, na perspectiva da formação de homens e mulheres civilizados e educados" (VEIGA e FARIA FILHO, 1997 p. 204). Nessa ambiência, a escola adquire centralidade no projeto político do novo regime, pois é vinculada à ideia de progresso e passa a ser encarada como recurso civilizatório para promover a "reforma dos costumes" com intuito de romper com o atraso e construir um Estado próspero e moderno.

Em consonância com os debates políticos realizados em outros estados brasileiros, os dirigentes mineiros afirmavam a necessidade de expandir a escola primária para erradicar o analfabetismo e construir o progresso na República. Imbuídos na crença de regeneração nacional por meio da escola, afirmavam a necessidade de formar o cidadão republicano "com autonomia moral, independente, mas perfeitamente ciente de sua cooperação na construção de uma obra - a cidade, a pátria, a humanidade" (FARIA FILHO, 1996 p. 302).

Amparados no pressuposto de que o papel do Estado era central na formulação e aplicação de uma política pública para o ensino primário, os governantes mineiros, sob a presidência de João Pinheiro, implementaram ampla reforma educacional em 1906 prescrevendo profundas alterações no campo educacional. A principal novidade foi a implantação dos grupos escolares como expressão de moderna e renovada organização da escola primária: a escola graduada concebida como "um modelo organizativo de escola nos moldes dos colégios de ensino secundário" baseado "fundamentalmente na classificação dos alunos pelo nível de conhecimento em agrupamentos supostamente homogêneos implicando a constituição das classes". (SOUZA, 2006 p. 13) Com características da escola graduada, os grupos escolares viabilizariam práticas educativas até então inéditas em Minas Gerais, reunindo vários professores em um mesmo prédio dirigido por um diretor escolar e organizando o ensino em séries anuais que formavam o curso primário de quatro anos nos quais os alunos seriam distribuídos de acordo com uma classificação homogênea pelo grau de adiantamento, sendo cada classe regida por um docente que ministrava o ensino simultaneamente aos alunos. (FARIA FILHO, 1996; SOUZA, 1998; CARVALHO, 2003; VIDAL 2006).

No projeto educacional republicano, não bastava somente instruir, era imprescindível uma educação integral cuja realização estava intimamente associada à remodelação das práticas educativas na sala de aula, a renovação dos métodos e processos de ensino e a introdução de novos saberes escolares apropriados à difusão de um conjunto de ideias, valores e comportamentos sociais capazes de manter e legitimar a ordem social e política constituída. Nessa ótica, os reformadores instituíram um programa único que deveria ser aplicado uniformemente nos grupos escolares e escolas isoladas, de acordo com os modernos métodos e processos educativos: "o ensino deverá seguir com rigor o método intuitivo e prático e terá por base o sistema simultâneo" (MINAS GERAIS, Regulamento da 
Instrução Primária e Normal do Estado de Minas Gerais, Decreto $\mathrm{n}^{\circ} 1.960$, de 16 de dezembro de 1906, Belo Horizonte, Imprensa Oficial do Estado, 1906 p. 11 ).

Partindo da crença de que a educação molda a nação e abre caminhos para a civilização, a disseminação uniforme de novas práticas de ensino torna-se condição necessária para garantir a todos uma educação pautada em novos valores culturais, morais e sociais. $\mathrm{Na}$ ótica dos políticos dirigentes, o conhecimento e controle do que se passava nas escolas primárias espraiadas pelo estado era fundamental para circunscrevê-las na perspectiva da moderna pedagogia e garantir a uniformização do ensino, que seria alcançada por meio da ação política coordenada e da capacidade controladora do governo estadual.

Nessa perspectiva, o serviço de inspeção escolar adquire particular relevância, sobretudo porque "corresponde à necessidade que tem a administração de conhecer, dia a dia, o estado da reforma do ensino em cada um dos institutos primários disseminados pela vastidão do território de Minas" (MINAS GERAIS. Relatório do secretário ao presidente do Estado. 1912. p. 347). Os reformadores criaram a Inspeção Técnica do Ensino com a função de modelar as práticas docentes de modo uniforme nas escolas primárias e relatar as intervenções realizadas de modo a dar visibilidade do movimento reformador por meio de relatórios quinzenais enviados à Administração Central, que buscava intervir continuamente no processo educativo.

$\mathrm{Na}$ lógica da política educacional pautada nos preceitos de uma "pedagogia moderna", na qual "a arte de ensinar é prescrita como boa imitação de práticas modelares" e "ensinar a ensinar é fornecer bons moldes" (CARVALHO, 2001, p. 143) os inspetores técnicos se configuram como modeladores do ensino dando a ver aulas exemplares aos professores nas escolas primárias do estado. Desse modo, foram incumbidos de fazer a mediação entre as estratégias de modelagem das práticas escolares e o alvo dessas estratégias: a prática docente (ISOBE, 2013).

Os reformadores pretendiam obter a concretização das mudanças pedagógicas estabelecidas e remodelar o ensino por meio de uma atuação constante dos inspetores nas escolas primárias na tentativa conformar, impor e produzir uma forma nova de se entender e praticar o ensino em Minas Gerais. Esse dispositivo evidencia a ação reguladora do Estado que procurava manter o processo educativo sob um olhar permanente por meio da visibilidade das práticas escolares dadas a ver nos relatórios da inspetoria técnica.

\section{Avaliação docente nos relatos de inspeção}

$6^{\mathrm{a}}$ Secção - Relatórios do sr. Ernesto Melo Brandão, inspetor técnico de Uberaba, relatório da $2^{\mathrm{a}}$ quinzena de julho p. findo. [...] Faz referencia a três professores da cidade de Uberaba: Fernando de Araújo Vaz de Melo, Carolina Augusta da S. e Evarista Modesta dos Santos. Não obstante pesarem sobre o professor Vaz de Melo acusações de praticar atos imorais, sobre o que a Secção já está tomando providências a fim de apurar sua culpabilidade, a sua escola é muito frequentada e a que sempre agrada mais aos inspetores técnicos. As duas professoras citadas cima, segundo diz o técnico, são inábeis, são rodas mortas no mecanismo de ensino primário. (MINAS GERAIS. Relatório de Inspeção. Inspetor Ernesto Mello Brandão. Uberaba. 31 de julho de 1909).

Este parecer, emitido pelo funcionário da $6^{\mathrm{a}}$ Seção da Secretaria do Interior encarregado de receber os relatórios dos inspetores técnicos, refere-se a uma questão 
constantemente denunciada naqueles documentos: apesar da assistência técnica prestada aos professores, muitos destes se comportavam como "rodas mortas no mecanismo do ensino", tornando improfícua a ação modeladora dos inspetores. As professoras "inábeis" mencionadas no parecer não seguem o ensino moderno oficial e utilizam "método defeituoso", enquanto o "bom" professor executa o programa "fielmente" e, embora acusado de prática de atos imorais, é competente e "sempre agrada mais aos técnicos".

No relatório sobre o qual foi emitido o parecer, o inspetor Ernesto Mello Brandão fala dos resultados satisfatórios encontrados na escola do professor que executa o programa "fielmente", utiliza o método intuitivo e cujos alunos têm bom aproveitamento, "confirmando ser bom o processo de ensino empregado". Ao contrário desta escola, o inspetor diz de outras duas que "não podem dar, como de fato não têm dado, um resultado satisfatório", pois não há "verdadeira" educação. Na ótica do inspetor, a causa disso é que as professoras não têm aptidão didática, preparo, inteligência e são incapazes de se aperfeiçoar, o que inviabiliza o sucesso da assistência técnica e das aulas modelares dadas pelo técnico do ensino "por dias consecutivos".

Visitando as escolas estaduais pertencentes ao município de Araguari, o inspetor Militino Pinto de Carvalho relata a falta de condições materiais e de "apetrechos pedagógicos" necessários ao bom funcionamento do ensino; sobre a assistência técnica prestada na escola do professor Levino Pinto Brandão, observa que

[...] apesar dessas faltas [materiais] dei instruções ao professor e creio que, bem instalada a escola e com mais assiduidade de visitas técnicas, o professor poderá entrar no regulamento vigente escolar porque é inteligente, assíduo tem algum preparo a alguma aptidão didática. (MINAS GERAIS. Relatório de Inspeção. Inspetor Militino Pinto de Carvalho. Araguari. 4 de junho de 1911)

No mesmo relatório, sobre a visita realizada na escola regida pela professora Maria Pia da Abadia, o inspetor afirma que esta

[...] encontra os maiores embaraços para dar execução ao programa ou regimento interno e toda e qualquer explicação que lhe seja ministrada por inspetor do ensino: faltam-lhe ao mais simples predicados para o magistério. Acho inútil qualquer assistência, mesmo demorada de autoridade escolar mandada àquela escola. (id. $I b$.)

Os relatórios de inspetoria técnica destacam que a eficácia do ensino moderno e da assistência técnica prestada pelos inspetores depende, sobretudo, do professor que deveria ter interesse, inteligência, preparo e aptidão didática para ser capaz de assimilar as "orientações" dos inspetores, colocar em prática os novos métodos e processos de ensino e realizar a evolução pedagógica pretendida. Sem tais requisitos, os professores são representados como "rodas mortas do ensino", incapazes de entender e aplicar os novos métodos, o que tem como consequência o atraso do ensino primário.

A maioria dos relatórios analisados evidencia que os atributos mais importantes são aqueles relativos à competência técnica, à capacidade intelectual dos docentes, mas não deixam aqueles documentos de indicar a importância do "amor à profissão" como condição significativa para que o docente se empenhasse no esforço pessoal para conseguir seu aperfeiçoamento técnico. O inspetor Athanásio Saltão, em inspeção realizada à $22^{\mathrm{a}}$ circunscrição, anota as péssimas condições da escola estadual do professor Gustavo Barros 
e afirma que este, embora inteligente e preparado, não executa o programa por falta de "amor à profissão":

[...] A única coisa que achei boa nesta escola foi a escrituração dos livros. A sala de todo não presta, pequena, soalhada em parte de tijolos e em parte de tábuas, forrada de uma soleira suja e muito baixa. Péssimo mobiliário. Pequeníssimo quadro-negro. Os alunos não podem fazer exercícios de caligrafia, porque na sala não há uma mesa para remédio, como se costuma dizer. Os 31 alunos que se achavam presentes, além de sujos, estavam se portando mal durante minha visita no dia 28 de abril. Atraso em toda a linha. [...] Entretanto, o sr Gustavo Barros é inteligente e preparado e se quisesse, isto é, se tivesse amor à profissão, seria excelente professor. (MINAS GERAIS. Relatório de Inspeção. Inspetor Athanásio Saltão. 01 de Junho de 1909).

O inspetor descreve as condições precárias da escola e o descumprimento do programa de ensino. Ressalva que o professor tem as competências técnicas necessárias para melhorar as condições da escola, "é inteligente e preparado", mas carece de "amor à profissão" para que possa executar o programa de ensino do governo. Desta forma, os requisitos técnicos de preparo, aptidão e capacidade intelectual associam-se ao interesse do professor pela causa do ensino. Para os agentes estatais, tais requisitos possibilitariam ao docente as condições essenciais para o entendimento e a execução do ensino moderno instituído com a Reforma: a assistência técnica seria eficiente e a escola daria "bons" resultados, de acordo com os preceitos da higiene e da moderna pedagogia.

\section{Entre prêmios e punições: modelando a prática docente}

PROFESSORES ELOGIADOS. Foram elogiados: d. Leopoldina Flora de Vasconcelos, professora em S. João Batista das Posses, município de Monte Santo, pelo asseio, ordem e disciplina encontrados em sua escola, conforme informações do inspetor técnicos da $24^{\mathrm{a}}$ Circunscrição Literária. [...] Pedro Nery, professor na cidade do Prata, pela regularidade na escrituração de sua escola, que acusa grande frequência, não poupando esforços para bem desempenhar suas funções; informação do inspetor técnico da $28^{\text {a }}$ Circunscrição Literária. [...] Tobias de Paula Pertence, professor em Piumi, pela solicitude, zelo e proficiência com que tem aplicado em sua escola o novo método de ensino; informação do inspetor técnico da $35^{a}$ Circunscrição. [...] d. Honorina Ventania, professora em Cataguases, pelo esforço no desempenho do cargo de preceptora inteligente e aplicada, traduzido na integral execução do programa, no adiantamento progressivo notado em sua escola e segura orientação pedagógica que imprime á sua direção, conforme consta do relatório do inspetor técnico de ensino da $14^{\text {a }}$ Circunscrição. [...] Fernando de Araújo Vaz de Mello, professor em Uberaba, pelo amor que tem revelado ás funções do magistério, mostrando-se verdadeiro paladino da nova organização do ensino. (MINAS GERAIS. Relatório do Secretário do Interior ao Presidente do Estado, 1908, p. 98-101)

Asseio, ordem, disciplina, frequência, zelo, proficiência na aplicação do novo método, inteligência, orientação pedagógica, execução integral do programa, amor ao 
magistério... Estes são alguns dos atributos do professor primário que mereciam os elogios da Secretaria do Interior, identificados a partir das informações constantes dos relatórios de inspetoria técnica do ensino.

A política de estímulo aos professores primários é particularmente evidente no envio de ofícios aos docentes, referindo-se às informações sobre eles e elas constantes nos relatórios de inspetoria técnica do ensino. Os elogios oficiais enviados pelo secretário do Interior eram como um atestado de que estavam cumprindo sua missão e agindo de acordo com os propósitos do governo. Além disso, os reformadores recompensavam os melhores professores com prêmios de viagens à capital para que pudessem conhecer as vantagens daqueles estabelecimentos modelares e ver a aplicação de novos métodos educativos. Os inspetores técnicos - "agentes de confiança do governo" - foram incumbidos de anotar suas observações solicitando os prêmios e indicando aqueles que apresentavam os requisitos necessários para assumir os cargos de direção dos grupos escolares.

As estratégias mobilizadas objetivavam incentivar o "bom professor" a continuar com os procedimentos legitimados pelos inspetores e estimular os outros docentes a seguir tais práticas. O relatório do Secretário do Interior, correspondente ao exercício de 1913, apresenta o resultado da avaliação dos professores "julgados ou classificados pela inspeção":

[...] verificou-se que os professores assim julgados ou classificados pela inspeção distribuem-se do seguinte modo: 536 são educadores de reconhecida competência e capazes da execução autonômica dos programas oficiais, desde que se lhes não oponha a deficiência de material didático, fato comum em localidades desprovidas de meios de comunicação; 452 são professores simplesmente bons, isto é, a quem falta algum requisito pedagógico para colocação em primeiro plano no magistério; 185 são professores sofríveis ou de poucos requisitos, necessitados de assistência, aguardando o governo o resultado desta para providenciar na conformidade do regulamento; 110 são maus docentes e, como tais, sujeitos desde que não se afastem espontaneamente do magistério ao processo de desclassificação se forem funcionários do Estado (MINAS GERAIS. Relatório do Secretário do Interior ao Presidente do Estado, 1913, p. 294)

Dentre todos os predicados desejados para o exercício do magistério, os de cunho pedagógico assumiam preponderância na classificação docente realizada pela Administração Central. Na ótica dos representantes do Estado os "melhores" professores eram os que apresentavam "reconhecida competência" que se referia à sua capacidade de "execução autonômica dos programas oficiais" o que implicava na desqualificação dos saberes e práticas que se diferiam dos referidos programas.

Os agentes do governo estadual mobilizavam estratégias de modelização da prática docente em um duplo movimento: por um lado, elogiava e recompensava os "bons" professores e, por outro, admoestava e punia os "maus" de acordo com a avaliação realizada pelos inspetores por meio das informações registradas nos relatórios quinzenais. Os dados eram arquivados "em um livro reservado existente na Secretaria" e seriam consultados sempre que necessário recorrendo-se a eles como a "base para recompensa ou punição dos atuais professores públicos e aproveitamento oportuno das pessoas que, não o sendo, queiram exercer o magistério". (MINAS GERAIS. Relatório do Secretário do Interior ao Presidente do Estado, 1909, p. 415.) 
Em várias situações, o Secretário do Interior solicitava informações a respeito dos professores indicados observando-se as notas que ficavam arquivadas na secretaria. A respeito dessa questão, deve-se sublinhar o caso da docente Amanda de Rezende Carvalho, normalista, nomeada para professora interina do grupo escolar de Araguari em 1914. Após quatro anos de exercício no magistério, a professora enviou um ofício ao Secretário do Interior requerendo efetividade naquele cargo e obteve a resposta de que não seria atendida por faltarem "predicados indispensáveis a uma boa professora" de acordo com as informações oferecidas pelos inspetores técnicos, arquivadas na Administração Central.

Além dos problemas relacionados às nomeações e efetividade no cargo os "maus" docentes recebiam ofícios do Secretário do Interior "chamando-lhes a atenção para as irregularidades dos institutos de que estão encarregados" (MINAS GERAIS. Relatório do Secretário do Interior ao Presidente do Estado, 1913, p. 294).

Porém, os ofícios de admoestação enviados aos professores nem sempre eram recebidos sem contestação por parte dos docentes, que se manifestavam contra as informações enviadas à Secretaria pelos inspetores técnicos. Desse fato é exemplo a correspondência enviada ao órgão por Francisca da Costa Souza, professora da escola isolada de Conquista, no distrito de Sacramento, em resposta ao ofício de admoestação que recebeu em 1908:

Exmo. sr. dr. Manoel Tomás de Carvalho Brito, d. secretário do Interior. Em resposta ao vosso ofício de 9 do corrente mês, cumpre-me dizer-vos que não me causou surpresa ter o sr. Atanásio Saltão, inspetor técnico, informado desfavoravelmente da minha cadeira; posso mesmo dizer que já esperava por isso, por ser S. Sa. inimigo de meu marido, que, por sua vez, lhe dispensa igual aversão. Posso provar com todos os pais de meus alunos e demais habitantes desta localidade que, desde a instalação da minha escola até esta data, nem um só dia deixei de ministrar o ensino como exige o programa em vigor, inclusive o canto e trabalhos manuais. S. Sa. visitou a minha escola no dia 11 de março, quarta-feira, demorando-se das onze e meia às doze e meia horas, isto é, uma hora de demora, e no dia 12 do mesmo mês, quinta-feira, das 11 horas até 1 hora, ou seja, o espaço de duas horas, isto é, fora da hora dos trabalhos manuais, e S. Sa. não pode afirmar, sem faltar à verdade, que não assistiu aos cantos nas horas regulamentares. Estou certa de que as informações falsas de qualquer inspetor têm para a Secretaria mais valor que as afirmativas verdadeiras de um professor primário; apesar disso, julgo-me com o direito, que a minha consciência me dá, de dizer que tudo quanto S. Sa. afirmou é falso! Causa dó ver como em Minas se deprime o trabalho de um professor primário. Saúde e fraternidade. Francisca da Costa Souza, professora. (MINAS GERAIS. Correspondências e ofícios 19 de Abril de 1908)

A professora contesta as informações negativas do inspetor técnico quanto à sua escola e as atribui à inimizade existente entre o inspetor e seu marido. Explicita sua opinião sobre a organização do serviço público mineiro, que "deprime o trabalho do professor primário". Sua crítica evidencia insatisfação para com os mecanismos de controle do trabalho docente, que dá credibilidade a "informações falsas de qualquer inspetor" e desvaloriza "afirmativas verdadeiras de um professor primário". Ela observa ainda que pode "provar com todos os pais dos meus alunos" que, em sua escola, desenvolve com rigor o programa de ensino, ou seja, recorre ao apoio das famílias para garantir a veracidade de suas palavras. Percebe-se o questionamento das relações de poder em função 
das ocupações dos cargos no sistema de ensino e a disputa sobre a legitimação das práticas no campo educativo.

\section{Considerações finais}

No âmbito de uma política educacional caracterizada pela ação reguladora e centralizadora do governo, as imagens do professor e da escola são construídas a partir da ótica dos agentes estatais especialmente destacados para modelar a prática educativa: os inspetores técnicos. Tais agentes deveriam transformar o olhar vigilante em palavra expressa nos relatórios que iriam, por sua vez, balizar as estratégias de modelização da prática docente.

No desempenho de suas funções, os inspetores técnicos tinham autoridade tanto para modelar a prática dos professores, quanto para constituir, a respeito deles, um julgamento capaz de medir suas qualidades, méritos e defeitos, representando-os como "bons" professores ou "rodas mortas do ensino" quanto aos seus saberes, suas práticas, enfim, sua competência profissional.

O olhar vigilante do Estado sobre os professores realizava-se por meio do dispositivo da inspetoria técnica que atuava sobre o processo educacional e, sobretudo, sobre a prática docente, a partir de um lugar de poder determinado, o lugar de um intérprete autorizado cuja ação visava aproximar as práticas dos professores das regras estabelecidas na conformação de novas práticas educativas nas escolas. Nessa conjuntura, os saberes e práticas escolares são produzidos por sujeitos diferenciados, hierarquicamente situados, cabendo aos inspetores técnicos realizar a modelização do processo educativo com base nos preceitos normativos e regulamentares elaborados de acordo com a moderna pedagogia e, portanto, autorizados como representantes do estado para distinguir o permitido e o proibido, o correto e o incorreto no processo educacional.

A análise evidencia os limites da ação reguladora dos sujeitos posicionados em uma instância superior na hierarquia estabelecida, pois esta não ocorreu sem conflitos, resistências e tensões da parte dos atores cujas práticas eram alvo das tentativas de controle. Os impasses desse processo são identificáveis, por exemplo, na insubmissão de alguns professores, que tentavam anular as admoestações e questionar as informações constantes nos relatórios e boletins da inspetoria.

Essas questões contribuem para dimensionar os caminhos percorridos no processo de constituição da escola pública brasileira evidenciando os conflitos entre os diferentes sujeitos, cujas práticas e representações são forjadas de acordo com os interesses dos grupos aos quais pertencem.

\section{Referências}

CARVAlHO, Marta. M. C. de. A escola e a República e outros ensaios. Bragança Paulista: Edusf: 2003

"A caixa de utensílios e a biblioteca: pedagogia e práticas de leitura" In: VIDAL,

Diana. G. \& HILSDORF, Maria. L. S. Tópicas de História da Educação, São Paulo: Edusp, 2001. p.137-167

CHARTIER, Roger. A História Cultural: Entre Práticas e Representações. Lisboa: Difel.1990 
FARIA FILHO, Luciano. M. de. Dos pardieiros aos palácios: forma e cultura escolares em Belo Horizonte (1906-1918), Tese de Doutorado em Educação — Faculdade de Educação, Universidade de São Paulo, 1996

ISOBE, Rogéria M. R. Inspeção técnica como dispositivo de formação de professores: estratégias de produção de um modelo escolar em Minas Gerais. Hist. Educ. (online). Porto Alegre, v. 17 n 39, jan/abr.2013, p. 9-21.

Educação e civilização no sertão: práticas de constituição do modelo escolar no triângulo mineiro (1906-1920). ). São Paulo: PUC/SP, 2004. (Tese de Dissertação Doutorado em Educação: História, Política, Sociedade). 2008

MINAS GERAIS. Regulamento da Instrução Primária e Normal do Estado de Minas Gerais, Decreto $\mathrm{n}^{\circ} 1.960$, de 16 de dezembro de 1906, Belo Horizonte, Imprensa Oficial do Estado, 1906. 1909.

Relatório de Inspeção. Inspetor Ernesto Mello Brandão. Uberaba. 31 de julho de 1911

Relatório de Inspeção. Inspetor Militino Pinto de Carvalho. Araguari. 4 de junho de

Relatório de Inspeção. Inspetor Athanásio Saltão. 01 de Junho de 1909

Relatório do Secretário do Interior ao Presidente do Estado, 1908

Relatório do Secretário do Interior ao Presidente do Estado, 1913.

Relatório do Secretário do Interior ao Presidente do Estado, 1909

Correspondências e ofícios 19 de Abril de 1908.

NUNES, Clarice. História da Educação Brasileira: novas abordagens de velhos objetos. Teoria \& Educação, n. 6, 1992, p. 151-182.

SOUZA, Rosa Fátima de. Templos de civilização: a implantação da escola primária graduada no Estado de São Paulo (1890-1910). São Paulo:UNESP, 1998.

. Alicerces da Pátria: Escola Primária e Cultura Escolar no Estado de São Paulo (1890-1976). Tese de Livre Docência em História da Educação. Araraquara: UNESP, 2006.

VEIGA, Cynthia G. e FARIA FILHO, Luciano M. de. "Belo Horizonte: a escola e os processos educativos no movimento da cidade". In: Vária História. Belo Horizonte, n¹8, 1997.

VIDAL, Diana. G. (org.). Grupos Escolares no Brasil: cultura escolar primária e escolarização da infância. Campinas: Mercado das Letras, 2006.

Recebido: abril/16 Aprovado: dezembro/16 